\title{
Introduction to Special Issue on Mine Water Inrushes: Risk Assessment, Mitigation, and Prevention
}

\author{
Shuning Dong ${ }^{1,2} \cdot$ Wanfang Zhou ${ }^{3} \cdot$ Hao Wang $^{1,2}$
}

Published online: 28 April 2021

๑) Springer-Verlag GmbH Germany, part of Springer Nature 2021

\begin{abstract}
Water inrush is a hazard that affects safety and production in many coal mines in China. Chinese mining engineers and scientists have made significant progresses in predicting, preventing, detecting, and mitigating this unique water hazard. The approximately 20 papers in this special issue present the latest research results and practices in six aspects: water inrush risk assessment, numerical simulation for water inrush prediction, high-resolution site characterization technique, rapid determination of water inrush point and water sources, early warning monitoring techniques, and engineering measures that have been used to prevent and mitigate water inrush events.
\end{abstract}

\section{Introduction}

Mine water inrushes occur when a large volume of water unexpectedly gushes into a mine, potentially inundating mine workings and causing casualties. These inrushes account for much of China's coal mine disasters and accidents and are the most serious in terms of economic losses, water resource damage, accident emergency rescue, and mine restoration difficulty. Surface subsidence, water resource reduction and contamination, and adverse impacts on biodiversity are examples of the indirect consequences of water inrushes. Prevention and mitigation of mine water inrushes is a challenging task and must respond to various complex and dynamic hydrogeological conditions, including concealed factors, changes in mining methods, and everevolving regulations. The challenges are more pronounced in large-scale mining of deeply buried coal seams. During

Wanfang Zhou

zhou_wanfang@yahoo.com

Shuning Dong

dongshuning@cctegxian.com

Hao Wang

wanghao@cctegxian.com

1 Xi' an Research Institute of China Coal Technology and Engineering Group, Xi' an, China

2 Shanxi Key Laboratory of Coal Mine Water Hazard Control, Xi' an, China

3 Zeo Environmental, Knoxville, TN, USA the past three decades, Chinese mining engineers and scientists have made important progress in predicting, preventing, detecting, and mitigating this unique water hazard. Approximately 20 papers were organized in this special issue (SI) to present the latest research results and practices in the following six aspects, i.e. water inrush risk assessment, numerical simulation for water inrush prediction, high-resolution site characterization technique, rapid determination of water inrush point and water sources, early warning monitoring technique for water inrush, and engineering measures to prevent and mitigate water inrush.

\section{Water Inrush Risk Assessment}

Water inrush risk assessment has been a required task for mine construction and production in China since 2009. Several papers in this SI describe the risk assessment processes and emphasize the importance of starting risk assessment along with development of a conceptual site model (CSM), in which the water sources and potential pathways to the mine's working area are identified. Although a water inrush CSM is site-specific, it typically includes three types of water sources: surface water (including infiltrating rainfall), water in closed mine pools, and groundwater.

Both hazards and risks must be considered in water inrush assessment. The degree of hazard and risk posed by an inrush is usually proportional to the amount of water, the water pressure, the pumping capacity of the mine, and the ecological sensitivity of the down-gradient environment to 
water regime changes. The CSM also describes the pathways from each source to various receptors. Direct exposure to water-bearing formations, mining-induced fractures in overlying or underlying aquicludes, hydraulically conductive faults and karst collapse columns, and poorly sealed boreholes are potential pathways that make water inrush possible. CSM development is an iterative process that reflects the progressive understanding of a mine, from initial hydrogeological investigation to water control during mining. Water inrush risk assessment should be performed with every update of the CSM.

\section{Numerical Simulations for Water Inrush Prediction}

Mine water inrush prediction has improved over the past 30 years. The empirical water inrush coefficient, which is defined as the ratio of the potentiometric pressure (in megapascals of the underlying aquifer and the aquiclude thickness (in meters) between the aquifer and coal seam, has been used for water inrush prediction from underlying aquifers since 1964. The water inrush coefficient reflects the most basic rule of groundwater seepage in hydrogeology, i.e. the core of Darcy's law. While the water inrush coefficient is still being used often with substitution of the effective aquiclude thickness for the traditional aquiclude thickness, integrated techniques including the vulnerability index approach have been developed to address the multi-factor, nonlinear, and dynamic water inrush processes. However, neither the empirical water inrush coefficient method nor the vulnerability index approach is physically based. Several papers included in this SI established physically-based inrush models and applied numerical simulations to study the water inrush processes. These mathematical exercises improved understanding of the water inrush mechanism and may lead to new prediction methods.

\section{High-Resolution Site Characterization Techniques}

Years of research, field tests, and analysis have provided great progress in underground geophysical technologies. Technologies now available for advanced detection of working face include direct current electrical resistivity imaging (ERI), transient electromagnetic (TEM), Rayleigh wave, induced polarization, 3-dimensional seismic high-resolution, ground penetrating radar, controlled source audio-frequency magnetotellurics, and sonar methods. The most commonly used methods are ERI and TEM. The advantage of the ERI method is that it is contact detection without blind spots, but it is only capable of single direction detection in front of the excavation face, with a detection distance between 60 and $80 \mathrm{~m}$. The volume effect is relatively large, and the interpretation is not unique. The advantage of the TEM method is multi-direction detection in underground roadway and the detection range is between 80 and $120 \mathrm{~m}$. The volume effect is relatively small. However, it does have an $\approx 20 \mathrm{~m}$ blind area and it is non-contact detection. More than one geophysical technique is typically recommended for advanced detection ahead of working faces. Audio-frequency electric imaging and TEM are used mainly to detect water-abundance of coal seam roof and floor aquifers, distribution of old mine pools, water-bearing structure, and permeable structures. Radio imaging, channel wave seismic, and elastic wave tomography methods are mainly used to detect coal structure and coal thickness change. Borehole geophysical logging and borehole hydrogeophysical logging have also made significant progresses. This SI includes papers that discuss applications of TEM, seismic imaging, and electrical sounding to identifying anomalous areas for water inrushes.

\section{Rapid Determination of Water Inrush Point and Water Source}

This SI includes papers describing methods to determine water inrush points and ascertain water sources when water inrushes occur. Water inrushes receive recharges from different types of water source such as precipitation, surface water, groundwater, and pooled water in closed mines. Rapid recognition of the inrush point and water source are critical in designing rescue plans and engineering measures to save lives and the affected mine. Multiple lines of evidence are typically collected and evaluated, and statistical analysis of multi-source information such as geochemistry, water pressure, and water temperature is essential. Databases are developed for various types of water sources to document their geophysical and geochemical characteristics such as water temperature, water level, or potentiometric pressure. Geological and geostatistical models were established for rapid recognition of inrush points and water sources for mine water inrushes based on the measured water pressure, temperature, and water chemistry.

\section{Early Warning Monitoring}

Water inrush symptoms may appear at different stages, including stress and strain changes in formations surrounding the mined-out areas, changes in groundwater levels or potentiometric pressure, changes in water inflow, chemistry, and temperature, and changes in gas characteristics and concentrations. Timely, accurately, and effectively capturing these symptoms requires development of a monitoring 
system for recognition and early warning. In-situ water hazard monitoring and early warning technology have been applied in many mines in China. A couple of papers in this SI discuss monitoring techniques that can minimize both false positive and false negative early warnings. These early warning systems use water pressure, water temperature, three-component strain grating sensors, and fiber grating communication technology. The high precision microseismic monitoring system provides real-time, dynamic, and planar diagnosis and stereo display of coal seam roof and floor deformation and failure processes, and geological structures such as faults and collapse columns.

\section{Engineering Measures to Prevent and Mitigate Water Inrush}

Compliance with the current regulatory policy of green and water-conservation mining requires careful evaluation of the traditional dewatering methods and implementation of innovative engineering measures, as illustrated in several papers of this SI. Underground directional drilling techniques including branch borehole-drilling technique and directional drilling allows advanced detection of adverse geological structure and changes in coal thickness and controlled dewatering of aquifers overlying or below the extractable coal seams and old mine pools. The advanced directional drilling of water exploration and dewatering can be oriented with directional settings, and the desired trajectory can be designed in accordance with the requirements. Directional drilling can substitute multiple straight drilling, greatly reducing drilling efforts. In addition, the position of directional drilling can be placed on the back of the development face to avoid interference between the advanced drilling and mining advance rate. Other advantages of directional drilling include small borehole density, high drilling trajectory controllability, multidirectional, parallel operation with excavating, accurate detection of target layer, and high discharge efficiency.

Development of directional drilling techniques makes it possible to implement target grouting proactively in a specific stratum on a regional scale or to seal off localized water pathways in response to water inrush incidents. For example, the grouting can be targeted to build water plugs in hydraulically conductive karst collapse columns to cut off water pathways from the underlying Ordovician limestone and build water-resistant walls in the water recharge roadway. In addition, the directional drilling and branch borehole-drilling techniques offer excellent prospects for directional grouting reinforcement of water-resistant layers and transformation of aquifers to aquicludes. Target grouting has been primarily used in thin-bedded limestone formations and the top of the Ordovician limestone. It is anticipated that proactive target grouting will become a preferred alternative in water inrush prone mines and mining areas at greater depths because it can eliminate potential water inrush disasters while preserving water resources.

\section{Summary}

Mine water inrushes have a variety of origins. Decades of investigation of and experience with water inrush prevention and mitigation in China make it clear that addressing the water inrush hazard requires a multi-disciplinary approach that integrates mining engineering, water resource engineering, engineering geology, hydrogeology, geophysics, geochemistry, and risk assessment. The inexorable and continuous changes of the ground and subsurface conditions in response to mining means that the occurrence of water inrushes is a dynamic process. The timing and extent of water inrushes are difficult to predict with $100 \%$ certainty. Prevention and mitigation of this hazard require continuous research on tools for positive identification of water inrush risk areas and continuous improvement of the best design practices and implementation of cost-effective engineering measures.

Acknowledgements Water inrush is a mine hazard that is important in certain geographic regions of the world. Editing of this SI has proved that obtaining objective and constructive reviews is not an easy task. Many papers required several rounds of review and revision. We appreciate all the reviewers who volunteered their time and knowledge to help improve quality of the papers. We also express our gratitude to Drs. Bob Kleinmann (Editor-in-Chief) and Anne Weber (Assistant to the Editor-in-Chief) of Mine Water and the Environment for their support and encouragement in making this SI possible. 